\title{
Variations in extensor tendons of the thumb -A cadaveric study
}

\author{
Biju Urumese Palatty ${ }^{1}$, Raveendranath Veeramani ${ }^{2, *}$, K.Y. Manjunath ${ }^{3}$ \\ ${ }^{\mathbf{1}}$ Associate Professor, Dept. of Anatomy, Amirta Institute of Medical Science, Amrita Vishwa Vidyapeetham, Kochi, Kerala, \\ ${ }^{2}$ Associate Professor, Dept. of Anatomy, Jawaharlal Institute of Postgraduate Medical Education and Research [JIPMER], \\ Dhanvantri Nagar, Pondicherry, ${ }^{3}$ Professor, Dept. of Anatomy, Annapoorna Medical College, Salem, Tamil Nadu, India
}

*Corresponding Author:

Email: dr_raveendra@ rediffmail.com

Received: $7^{\text {th }}$ February, 2018

Accepted: $13^{\text {th }}$ April, 2018

\begin{abstract}
Introduction and Aims: The movements of the thumb are carried out by three muscles originating from the forearm viz., two extensors (a longus and a brevis) and an abductor. Anatomical variation has been observed in one out of every six cadavers. Among the muscles of the thumb the abductor is commonly known to show such variations. Aim of this report is to present the frequency of variations in local population.

Materials and Methods: The data for the present study was collected by dissection of fifty hands (30 adult and 20fetal).Tendon slips of each of the three muscles were counted and their width was measured with a calliper.

Observations: A single tendon slip of extensor pollicis longus was found in $43(86 \%)$ hands, and in seven (14\%) the tendon slip was duplicated. The extensor pollicis brevis tendon was found to have a single slip in 47 (94\%) hands and in three (6\%) the tendon slip was duplicated. The abductor pollicis longus tendon (APL) had a single slip in 38(76\%) hands, double and triple together in 11(22\%). The APL was absent in one (2\%) hand. In one adult male the APL had three slips of origin; anterior slip formed a fusiform belly attached to the base of the proximal phalanx. On the left side of the same cadaver the muscle had two slips, the anterior slip divided into two, one of these ended in a fusiform belly within the thenar eminence.

Conclusions: Knowledge of anatomical variations of the tendons of the thumb is essential during the surgical repair and in cases where tendon transfer is required. Multiple tendons are known to cause conditions like de Queverain's syndrome.
\end{abstract}

Keywords: Thumb, Extensors, Forearm, Variations.

\section{Introduction}

The movements of the thumb are unique to human species, this accords superiority to us in comparison to other animals. The movements of the thumb are carried out by three muscles taking origin from the posterior compartment of the forearm viz., two extensors (a longus and a brevis) and an abductor. ${ }^{1}$ A number of anatomical variations of these muscles have been reported to occur in every sixth cadaver by earlier workers. Of the three muscles the abductor pollicis longus (APL) is commonly known to be variable. Sometimes the extensor pollicis brevis (EPB) may be absent due to fusion with the APL. The Extensor Pollicis Longus (EPL) may be duplicated or it may be absent $(1.5 \%){ }^{2-5}$ Knowledge of the variations of the tendons is important to the surgeon while carrying out repair or transfer of tendons. Clinical condition like de Queverain's syndrome has been attributed to the presence of accessory tendons of thumb muscles. ${ }^{6}$

\section{Materials and Methods}

The present study was an observational study carried out using 50 upper limbs of embalmed cadavers (15 adult and 10 foetuses). Cadavers having any hand anomalies, marks of gross injuries, fractures, and tumours were excluded from the study.

The tendons were exposed using standard dissection procedure as described in dissection manuals of anatomy. The tendons of the thumb muscles were identified after exposure, cleaned and the width of the tendon slips was measured with a digital calliper to the nearest millimetre and the number of tendon slips were counted. The results were statistically analyzed for the following parameters, viz., mean, standard deviation, range, side and sex dominance.

\section{Observations}

Variations of the size of the tendons are presented in tables 1, 2, 3, 4 and 5 .

Extensor Pollicis Longus: a) Number of tendon slips: In all the specimens (adults and foetuses included)-a single tendon slip was found in $43(86 \%$ ) hands, and in the remaining seven (14\%) the tendons were duplicated. Adult Hands: A single tendon slip was found- in $23(77 \%)$ hands, in the remaining seven $(23 \%)$ tendons were duplicated.

Fetal Hands: EPL tendons were single stranded in $100 \%$ of the hands.

Width of the Tendon Slips: The range of the width of the tendon slips was $1.6 \mathrm{~mm}$ to $5.05 \mathrm{~mm}$ in adult males and $1.70 \mathrm{~mm}$ to $4.4 \mathrm{~mm}$ in adult females. In fetal hands the width of the tendon slips was in the range of 0.95 $\mathrm{mm}$ to $1.99 \mathrm{~mm}$ in males and $0.8 \mathrm{~mm}$ to $1.96 \mathrm{~mm}$ in females.

Extensor Pollicis Brevis: The observations on the EPB in the present study are as follows: a) Number of tendon slips: In all the specimens (adults and foetuses included), -a single tendon slip was found in $47(94 \%)$ 
hands, and in three $(6 \%)$ hands the tendon slips were duplicated.

Adult Hands: A single tendon was found in 27(90\%), instances in the other three (10\%) it was duplicated.

Foetal Hands: A single EPB tendon was found in $19(95 \%)$ hands and in one (5\%) it was duplicated.

The Width of the EPB Tendon: adult males - $1.6 \mathrm{~mm}$ to $4.95 \mathrm{~mm}$ and adult females- $1.76 \mathrm{~mm}$ to $5.16 \mathrm{~mm}$. Foetuses $-0.88 \mathrm{~mm}$ to $1.98 \mathrm{~mm}$ in males and $0.4 \mathrm{~mm}$ to $1.8 \mathrm{~mm}$ in females.

Abductor Pollicis Longus (Fig. 1-3):

The variations of APL tendon in the present study are shown in the tables 1, 2, 3 and 6

Number of Tendon Slips: In all the specimens (adults and foetuses included), a single tendon- in 38(76\%) hands, double and triple strands were found in 11(22\%). APL was absent in one (2\%) hand.

Adult Hands: single tendon in -20(67\%) hands, double and triple tendons in-10 (33\%) hands.

Foetal Hands: In one (5\%) of the foetal hands APL was absent. A single tendon slip in -18(90\%) specimens and double tendons were found in one (5\%) specimen.

The Width of the APL Tendon: Adult males $-1.36 \mathrm{~mm}$ to $12.46 \mathrm{~mm}$ and in Adult females- $1.52 \mathrm{~mm}$ to 5.00 $\mathrm{mm}$. Foetuses : Males $-0.99 \mathrm{~mm}$ to $2.00 \mathrm{~mm}$; Females $01.04 \mathrm{~mm}$ to $1.94 \mathrm{~mm}$.

\section{Discussion}

The thumb plays a key role in the movements of human hand. The three long muscles attached to the thumb viz., EPL, EPB and APL are of utmost importance in its movements. Occurrence of multiple tendons of these muscles has been reported by several earlier workers. ${ }^{3-6}$ The disturbances in joint movements may be attributed to the presence of multiple tendons around the joint.

Extensor Pollicis Longus (Fig. 5): Arises from the ulna, and the interosseous membrane and, is inserted to the terminal phalanx of the thumb.

Duplication of this muscle has been reported frequently. ${ }^{1,6}$ In $1.5 \%$ of individuals it may be absent. ${ }^{4}$ Thwin et al., ${ }^{7}$ and Nishijo et al., ${ }^{8}$ have reported double EPL tendons. Abdel-Hamid et al., ${ }^{9}$ have reported single tendons of EPL in $67.4 \%$ and duplicated tendons in $32.6 \%$. Tendon transfer surgery may be necessary in cases of Colles' fracture complicated with rupture of the EPL tendon. ${ }^{10,11}$

An occasionally occurring muscle, known as extensor pollicis et indicis has been reported by Wood, and MacAlister. ${ }^{12,13}$ The dog, fox, wolf, jackal, panther, and the dingo are known to possess a similar muscle. When present it takes origin from the ulna and its tendon divides into two, attached one to the thumb, and the other to the index finger. However no such muscle was found in present study. The number and size of the EPL tendons as observed in the present study is presented in Tables 1-3.
Extensor Pollicis Brevis: Arises from the shaft of the radius, and from the interosseous membrane. It is inserted into the first phalanx of the thumb. ${ }^{1} \mathrm{EPB}$, is a muscle unique to man. A number of variations of this muscle are known: it may be absent being fused with APL, its tendon may be united with EPL and inserted with it. ${ }^{5}$ Sabnis $^{6}$ has reported duplication of EPB. Mode of insertion of EPB is variable: according to a study it was attached to first phalanx in $72 \%$; both phalanges $21 \%$, and the terminal phalanx, in $6.8 \% .{ }^{4.5}$ In $6.3 \%$ of cases it may be absent. In another study it was absent in five instances out of 120 limbs. ${ }^{4,5}$

Abdel-Hamid et al., have reported absence of EPB in $2.1 \% .^{9}$ Nayak et al., ${ }^{17}$ have reported a case of absence of EPB. The muscle may split in to two, one of which gets attached to the first metacarpal. ${ }^{4,5}$ Wood $^{12}$ and Mori et al ${ }^{14}$ have also reported absence of EPB in their studies.

The observations on the EPB in the present study are shown in the tables 1-3. No case of absence of EPB was found in the present study.

Abductor Pollicis Longus: arises from the shafts of the ulna, and radius and the interosseous membrane. It is inserted into the base of the first metacarpal bone. ${ }^{1}$

Abductor pollicis tertius (extensor alque abductor pollicis accessorius), a rare muscle, arises from the radius with APL and inserts, after fusion with abductor pollicis brevis, to the first metacarpal. Variation of thumb muscles has been observed in every sixth cadaver. The most frequent variations occur in the APL which may be a splitting of its tendon, or the whole muscle or duplication of the belly of the muscle. The APL may be reduced to a small slip arising only from the radius. Its tendon may be attached to the flexor retinaculum, carpal bones, APB, opponens pollicis (OP), first phalanx, or the tendon may be inserted on to the first metacarpal. An additional tendon may give origin to OP. ${ }^{4,5}$ Thwin et al., ${ }^{7}$ found multiple tendon slips of the APL(3 to 14 slips). Five, six and even nine tendon slips of the APL have been reported. ${ }^{15-17} \mathrm{Baba},{ }^{18}$ has reported $95 \%$ of APL having multiple tendons. They were inserted into APB in $25 \%$, the trapezium, joint capsule, fascia in $34 \%$. Lacey et al., ${ }^{19}$ found only seven APL muscles out of 38 with a single tendon, 20 had two, and six had three tendons. Among the cases with a second tendon, the other tendon was inserted into the tendon of APB or, onto the trapezium. Among the cases of triple tendons, tendons were inserted to the $\mathrm{APB}$, to the trapezium, or to the tendon of OP. In another study, ${ }^{4} 10.2 \%$ of the APL had a single tendon that inserted to the first metacarpal only. In other cases a dual insertion to the APB, the trapezium, or into the $\mathrm{OP}$, or to the first phalanx was observed. The variations of APL tendon in the present study are shown in the tables 1-3.

Variant and Anomalous Tendons of the Thumb: Vaclave ${ }^{20}$ has described two varieties of the multiple tendons of the supernumerary muscles of the forearm. 
Chiu ${ }^{21}$ has observed a supernumerary extensor tendon to the thumb in a black female. Abu-Hijleh ${ }^{22}$ has reported - a case of an extra extensor muscle of the right thumb. Joshi and Joshi ${ }^{23}$ have observed that in more than $80 \%$ cases the tendon of APL is double or multiple. Sarikcioglu and Yildirim ${ }^{24}$ report seven tendons of the APL and APB in the same compartment.
Anomalous bellies of origin of APL in the present study (see Fig. 4): In one adult male cadaver APL had three slips of origin, anterior most formed a fusiform belly attached to the proximal phalanx in a right hand of an adult male. In the left hand of the same cadaver the muscle had two slips, anterior slip divided into two, one of these ended in a fusiform muscle belly. Other slip ended in the base of first metacarpal.

Table 1: Combined incidence of number of tendons of each extensor muscle to thumb of the both adult and fetal hands

\begin{tabular}{|l|c|c|c|c|}
\hline \multirow{2}{*}{ Name of the muscle } & \multirow{2}{*}{$\begin{array}{c}\text { Side } \rightarrow \\
\text { No. of tendons } \downarrow\end{array}$} & \multicolumn{3}{|c|}{ Incidence (\%)n= no of hand s } \\
\cline { 3 - 5 } & Right hand $\mathbf{n = 2 7}$ & Left hand $\mathbf{n = 2 3}$ & Total $\mathbf{n = 5 0}$ \\
\hline Abductor pollicis longus & Absent & $1(4)$ & $0(0)$ & $1(2)$ \\
& Single & $22(81)$ & $16(69)$ & $38(76)$ \\
& Double & $3(11)$ & $5(22)$ & $8(16)$ \\
& Triple & $1(4)$ & $2(9)$ & $3(6)$ \\
\hline Extensor pollicis brevis & Single & $25(92)$ & $22(96)$ & $47(94)$ \\
& Double & $2(8)$ & $1(4)$ & $3(6)$ \\
\hline Extensor pollicis longus & Single & $26(96)$ & $17(74)$ & $43(86)$ \\
& Double & $1(4)$ & $6(26)$ & $7(14)$ \\
\hline
\end{tabular}

Table 2: Incidence of number of tendons of each extensor muscle to thumb in adult hands

\begin{tabular}{|l|c|c|c|c|}
\hline \multirow{2}{*}{ Name of the muscle } & & \multicolumn{3}{|c|}{ Incidence (\%) } \\
\cline { 2 - 5 } & No of tendons & Male $\mathbf{n = 2 1}$ & Female n = 9 & Total n = 30 \\
\hline Abductor pollicis longus & Single & $14(67)$ & $6(67)$ & $20(67)$ \\
& Double & $5(23)$ & $2(22)$ & $7(23)$ \\
& Triple & $2(10)$ & $1(11)$ & $3(10)$ \\
\hline Extensor pollicis brevis & Single & $19(90)$ & $8(89)$ & $27(90)$ \\
& Double & $2(10)$ & $1(11)$ & $3(10)$ \\
\hline Extensor pollicis longus & Single & $18(86)$ & $5(56)$ & $23(77)$ \\
& Double & $3(14)$ & $4(44)$ & $7(23)$ \\
\hline
\end{tabular}

Table 3: Incidence of number of tendons of each extensor muscle to thumb in fetal hands

\begin{tabular}{|l|c|c|c|c|}
\hline Name of the muscle & & Incidence (\%) & Incidence (\%) & Incidence (\%) \\
\cline { 2 - 5 } & No: of tendons & Male $\mathbf{n = 1 2}$ & Female $\mathbf{n = 8}$ & Total $\mathbf{~}=\mathbf{2 0}$ \\
\hline Abductor polllicis longus & Absent & $1(8)$ & $0(0)$ & $1(5)$ \\
& Single & $10(84)$ & $8(100)$ & $18(90)$ \\
& Double & $1(8)$ & $0(0)$ & $1(5)$ \\
\hline Extensor pollicis brevis & Absent & $0(0)$ & $0(0)$ & $0(0)$ \\
& Single & $12(100)$ & $7(87)$ & $19(95)$ \\
& Double & $0(0)$ & $1(13)$ & $1(5)$ \\
& Triple & $0(0)$ & $0(0)$ & $0(0)$ \\
& Multiple & $0(0)$ & $0(0)$ & $0(0)$ \\
\hline Extensor pollicis longus & Single & $12(100)$ & $8(100)$ & $20(100)$ \\
\hline
\end{tabular}

Table 4: Side and the number of tendinous slips of each extensor muscle to the thumb: Extensor pollicis longus

\begin{tabular}{|l|c|c|}
\hline \multicolumn{1}{|c|}{ Right side } & $\begin{array}{c}\text { Number of Tendons } \\
\text { (No: of sides found) }\end{array}$ & $\begin{array}{c}\text { Width } \\
\text { (Mean } \pm \text { SD; Range) }\end{array}$ \\
\hline Adult Males (11) & $0(0) ; 1(10) ; 2(1) ; 3(0) ; 4(0)$ & $(3.61 \pm 0.77 ; 2.54-5.06)$ \\
\hline Adult Females (5) & $0(0) ; 1(5) ; 2(0) ; 3(0) ; 4(0)$ & $(3.02 \pm 0.2 ; 2.73-4.1)$ \\
\hline Fetus Male (6) & $0(0) ; 1(6) ; 2(0) ; 3(0) ; 4(0)$ & $(1.32 \pm 0.36 ; 0.95-1.99)$ \\
\hline Fetus Female (5) & $0(0) ; 1(5) ; 2(0) ; 3(0) ; 4(0)$ & $(1.45 \pm 0.41 ; 0.84-1.96)$ \\
\hline Left side & & \\
\hline Adult Males (10) & $0(0) ; 1(8) ; 2(2) ; 3(0) ; 4(0)$ & $(3.01+1.11 ; 1.66-4.99)$ \\
\hline Adult Females (4) & $0(0) ; 1(0) ; 2(4) ; 3(0) ; 4(0)$ & $(3.01+0.93 ; 1.7-4.4)$ \\
\hline Fetus Male (6) & $0(0) ; 1(6) ; 2(0) ; 3(0) ; 4(0)$ & $(1.43+0.41 ; 1-1.9)$ \\
\hline Fetus Female (3) & $0(0) ; 1(3) ; 2(0) ; 3(0) ; 4(0)$. & $(1.05+0.36 ; 0.8-1.3)$ \\
\hline
\end{tabular}

$\mathrm{n}=$ number of hands observed 
Table 5: Side and the number of tendinous slips of each extensor muscle to the thumb: Extensor pollicis brevis

\begin{tabular}{|l|c|c|}
\hline \multicolumn{1}{|c|}{ Right side } & $\begin{array}{c}\text { Number of Tendons } \\
\text { (No: of sides found) }\end{array}$ & $\begin{array}{c}\text { Width } \\
\text { (Mean } \pm \text { SD; Range) }\end{array}$ \\
\cline { 2 - 3 } & $0(0) ; 1(10) ; 2(1) ; 3(0) ; 4(0)$ & $(2.95 \pm 0.85 ; 1.6-4.05)$ \\
\hline Adult Males (11) & $0(0) ; 1(5) ; 2(0) ; 3(0) ; 4(0)$ & $(3.14 \pm 1.13 ; 1.76-4.05)$ \\
\hline Adult Females (5) & $0(0) ; 1(6) ; 2(0) ; 3(0) ; 4(0)$ & $(1.5 \pm 0.37 ; 0.91-1.88)$ \\
\hline Fetus Male (6) & $0(0) ; 1(4) ; 2(1) ; 3(0) ; 4(0)$ & $(1.16 \pm 0.6 ; 0.4-1.8)$ \\
\hline Fetus Female (5) & & \\
\hline Left side & $0(0) ; 1(9) ; 2(1) ; 3(0) ; 4(0)$ & $(3.26 \pm 0.94 ; 2.03-4.95)$ \\
\hline Adult Males (10) & $0(0) ; 1(4) ; 2(0) ; 3(0) ; 4(0)$ & $(3.4 \pm 1.5 ; 2.2-5.16)$ \\
\hline Adult Females (4) & $0(0) ; 1(6) ; 2(0) ; 3(0) ; 4(0)$ & $(1.38 \pm 0.46 ; 0.88-1.98)$ \\
\hline Fetus Male (6) & $0(0) ; 1(3) ; 2(0) ; 3(0) ; 4(0)$ & $(1.17 \pm 0.46 ; 0.65-1.53)$ \\
\hline Fetus Female (3) & & \\
\hline
\end{tabular}

$\mathrm{n}=$ number of hands observed

Table 6: Side and the number of tendinous slips of each extensor muscle to the thumb: Abductor Pollicis Longus

\begin{tabular}{|l|c|c|}
\hline \multicolumn{1}{|c|}{ Right side } & $\begin{array}{c}\text { Number of Tendons } \\
\text { (No: of sides found) }\end{array}$ & $\begin{array}{c}\text { Width } \\
\text { (Mean } \pm \text { SD; Range) }\end{array}$ \\
\hline Adult Males (11) & $0(0) ; 1(8) ; 2(2) ; 3(1) ; 4(0)$ & $(3.09 \pm 0.82 ; 1.86-5.1)$ \\
\hline Adult Females (5) & $0(0) ; 1(4) ; 2(1) ; 3(0) ; 4(0)$ & $(3.3 \pm 1.06 ; 1.52-4.82)$ \\
\hline Fetus Male (6) & $0(1) ; 1(5) ; 2(0) ; 3(0) ; 4(0)$ & $(1.4 \pm 0.46 ; 0.99-2)$ \\
\hline Fetus Female (5) & $0(0) ; 1(5) ; 2(0) ; 3(0) ; 4(0)$ & $(1.4 \pm 0.35 ; 1.04-1.94)$ \\
\hline Left side & & \\
\hline Adult Males (10) & $0(0) ; 1(6) ; 2(3) ; 3(1) ; 4(0)$ & $(3.7 \pm 2.6 ; 1.36-12.46)$ \\
\hline Adult Females (4) & $0(0) ; 1(2) ; 2(1) ; 3(1) ; 4(0)$ & $(3.4 \pm 0.93 ; 2.3-5)$ \\
\hline Fetus Male $(6)$ & $0(0) ; 1(5) ; 2(1) ; 3(0) ; 4(0)$ & $(1.4 \pm 0.19 ; 1.18-1.68)$ \\
\hline Fetus Female (3) & $0(0) ; 1(3) ; 2(0) ; 3(0) ; 4(0)$ & $(1.48 \pm 0.14 ; 1.34-1.62)$ \\
\hline
\end{tabular}

$\mathrm{n}=$ number of hands observed

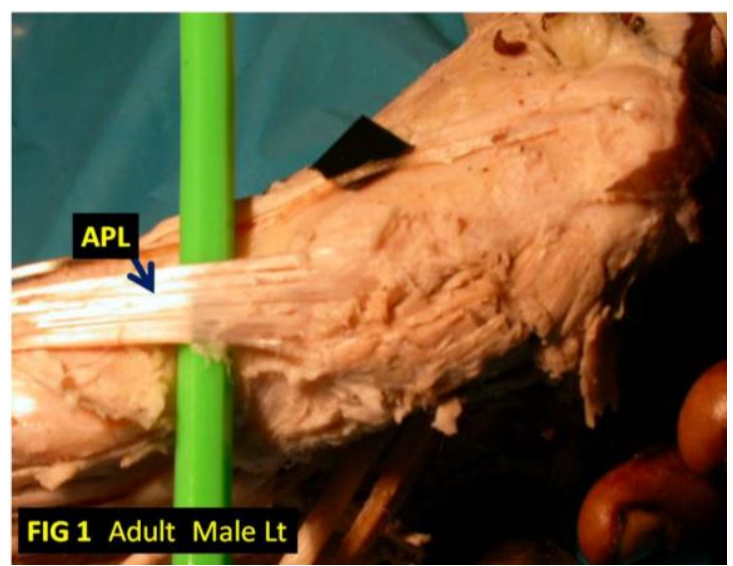

Fig. 1: Adult male left hand. Abductor pollicis longus (APL): splits into six slips with a total width of $12.46 \mathrm{~mm}$.

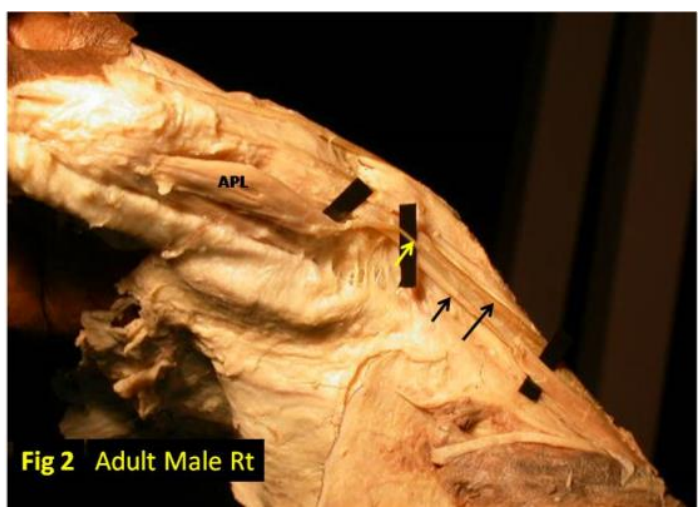

Fig. 2: Adult male right hand. Abductor pollicis longus (APL): three slips, anterior most slip (width$1.86 \mathrm{~mm}$ ) ends in a fusiform belly attached to the base of the proximal phalanges the muscle belly measures width $-10.39 \mathrm{~mm}$; length $-36.67 \mathrm{~mm}$, supplied by median nerve. 


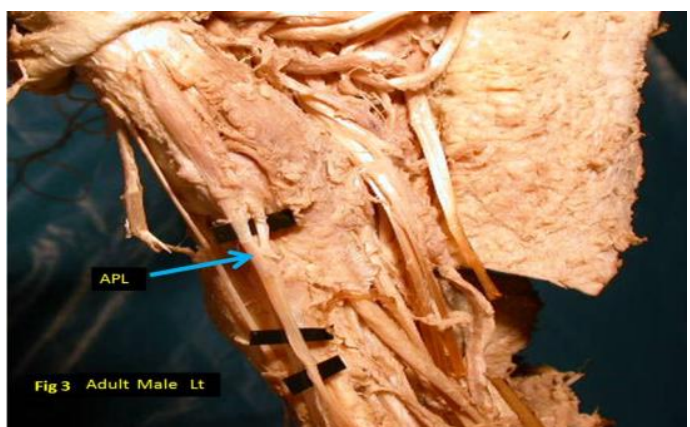

Fig. 3: Adult male left hand. Abductor pollicis longus: Two slips (width-3.77mm and 5.44mm); anterior most slip divides into two, one of these ends in a fusiform muscle belly (length-37.28mm; width$8.83 \mathrm{~mm}$ ) with the thenar eminence. Other slip ends in the base of first metacarpal. Second slip ends in the base of first metacarpal.

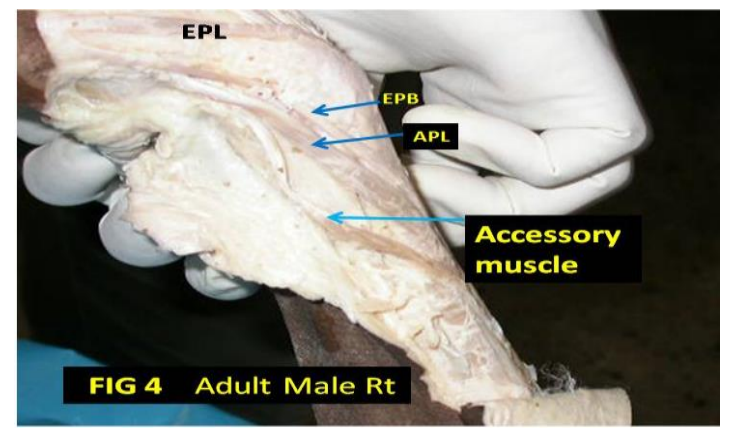

Fig. 4: Adult male right hand. Abductor pollicis longus: Single tendon, width-2.72mm. Accessory muscle present: Originated from the tendon of radialis longus, brevis and brachioradialis dividing into a number of strands attached to the shaft of the base of first metacarpal: Muscle belly ;length42.87mm width-5.14mm:Tendon ;length- $46.65 \mathrm{~mm}$ width $-1.25 \mathrm{~mm}$.

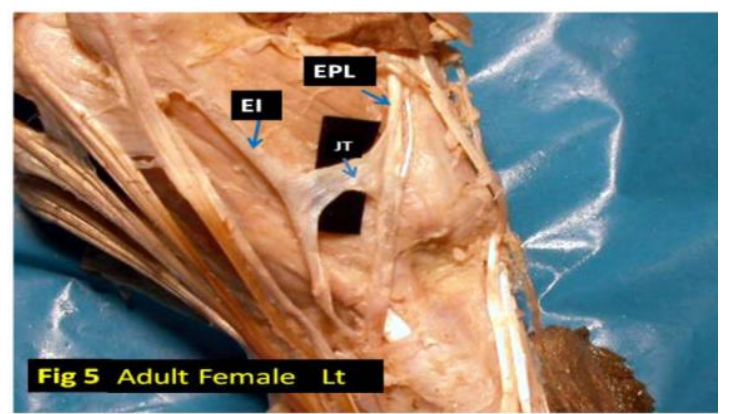

Fig. 5: Adult female left hand. Extensor pollicis longus: single tendon $2.99 \mathrm{~mm}$ Extensor pollicis brevis: Single tendon $3.7 \mathrm{~mm}$. Abductor pollicis longus: Three slips width $3.72 \mathrm{~mm}, 5.16 \mathrm{~mm}$, and $2.66 \mathrm{~mm}$. Anterior slip divides into two; a thin strand merges with thenar muscle. All other stands attached to the base of the first metacarpal. Juncture tendinum between; Extensor pollicis longus tendon and the lateral slip of extensor indicis length-15.87mm; width-5.54mm.

\section{Conclusion}

Multiple variations, including supernumerary tendon slips of the thumb muscles were seen in the present study. The occurrence of multiple tendons is of clinical importance for the management of de Queverain's syndrome. Detailed knowledge of these variations is of help in interventional radiology in diagnosing tendon rupture, but also during orthopaedic surgery during tendon transfer.

\section{References}

1. Standring S, Johnson D \& Ellis H(Eds). Gray's Anatomy. The anatomical basis of clinical practice. Edinburgh, Churchill Livingstone, 39 th edn.2005. p.882.

2. Rao MKG, Vollala V. Four cases of variations in the forearm extensor musculature in a study of hundred limbs. Indian J of Plastic Surgery. 2006;39(2):141-147.

3. Hirai Y, Yoshida K, Yamanaka K, Inoue A, Yamaki K, Yoshizuka M. An anatomic study of the extensor tendons of the human hand. J Hand Surg [Am]. 2001; 26(6):10091015 .

4. Bergman RA, Thompson SA, Affifi AK, Saadeh FA. (Eds).Compendium of human anatomic variation: catalog, atlas and world literature. Urban \& Schwarzenberg, Baltimore and Munich. 1988.

5. Akita K and Nimura A. in chapter 33: Forearm muscles. Bergman's Comprehensive Encyclopedia of Human Anatomic Variation. Tubbs RS, Shoja, MM, Loukas M (Eds) John Wiley \& Sons, Inc. Wiley online library. 2016; p. 307.

6. Sabnis AS. Anatomical variations of long tendons of the thumb. Int J Cur Res Rev. 2013;5(07):41-45.

7. Thwin SS, Zaini F, Than M. Multiple variations of the tendons of the anatomical snuffbox. Singapore Med J. 2014;55(1):37-40.

8. Nishijo K, Kotani H, Miki T, Senzoku F, Ueo T. Unusual course of the extensor pollicis longus tendon associated with tenosynovitis, presenting as de Quervain Disease--a case report. Acta Orthop Scand. 2000;71:426-28.

9. Abdel-Hamid GA, El-Beshbishy RA, Abdel Aal IH. Anatomical variations of the hand extensors. Folia Morphol. 2013;72(3):249-257.

10. Trevor D. Rupture of the extensor pollicis longus tendon after Colles fracture. J Bone Joint Surg (Br). 1950;32B:370-5.

11. Magnussen PA, Harvey FJ, Tonkin MA. Extensor indicis proprius transfer for rupture of the extensor pollicis longus tendon. J Bone Joint Surg (Br). 1990;72:881-3.

12. Wood J. Variations in human myology observed during the winter session of 1867-68 at King's College. London. Proc Roy Soc. Lond. 1868;17:483-525.

13. Macalister A. An additional observation on muscular anomalies in human anatomy. Trans Roy Irish Acad Sci. $1875 ; 25: 1-134$

14. Mori H, Ishikawa H, Hirata S. Rheumatoid Nodule on the Extensor Tendon of the Wrist. J Bull Health Sci Kobe. 1999;15(1):97-101.

15. Mansur DI, Krishnamurthy A, Nayak SR, Kumar CG, Rai R, Sujatha D'Costa S, Prabhu LV. Multiple tendons of abductor pollicis longus. Int J Anat Var. 2010;3:25-6.

16. Akan M, Gideroglu K, Cakir B. Multiple tendons of the abductor pollicis longus muscle. Hand Surg. 2002;7:28991. 
17. Nayak SR, Krishnamurthy A, Pai MM, Prabhu LV, Ramanathan LA, Ganesh Kumar C, Thomas MM Multiple variations of the extensor tendons of the forearm. Rom J of Morphol and Embryol. 2008;49:97100.

18. Baba MA. The accessory tendon of the abductor pollicis longus muscle. Anat Rec. 1954;119(4):541-547.

19. Lacey T, Goldstein LA, Tobin CE.Anatomical and clinical study of the variations in the insertions of the abductor pollices longus tendon, associated with stenosing tendovaginitis. J Bone Joint Surg (Am). 1951;33(2):347-350.

20. Vaclavek J. Correlation of the dorsal tendinous variations of the hand with the arrangement of the entire tendinous extensor to the back of the finger in man. Bull Assoc Anat (Nancy). 1975; 59(167):995-999.

21. Chiu DT. Supernumerary extensor tendon to the thumb: a report on a rare anatomic variation. Plast Reconst Surg. 1981;68(6):937-9.
22. Abu-Hijleh MF. Extensor pollicis tertius: an additional extensor muscle to the thumb. Plast Reconstr Surg. 1993;92(2):340-343.

23. Joshi SS and Joshi SD. Applied Significance of Variations of the First Extensor Compartment of Wrist. $J$ Anat Soc. India. 2002;51(2):159-161.

24. Sarikcioglu L, Yildirim FB. Bilateral abductor pollicis longus muscle variation: Case report and review of the literature. Morphologie. 2004;88(282):160-163.

How to cite this article: Palatty BU, Veeramani R, Manjunath KY. Variations in extensor tendons of the thumb $-\mathrm{A}$ cadaveric study. Ind J Clin Anat Physiol. 2018;5(3):383388 . 